\title{
An Analysis on Academicians Job Satisfaction in the Perspective of HRD Practices
}

\author{
Choi Sang Long ${ }^{1}$, Sia Shi Xuan ${ }^{2}$, Wan Khairuzzaman Wan Ismail ${ }^{3}$, Siti Zaleha Abd Rasid ${ }^{3} \&$ Tan Owee Kowang ${ }^{1}$ \\ ${ }^{1}$ Faculty of Management, Universiti Teknologi Malaysia, Johor Bahru, Malaysia \\ ${ }^{2}$ Tunku Abdul Rahman University College, Johor Bahru, Malaysia \\ ${ }^{3}$ International Business School, Universiti Teknologi Malaysia, Kuala Lumpur, Malaysia \\ Correspondence: Choi Sang Long, Faculty of Management, Universiti Teknologi Malaysia, 81310 Johor Bahru, \\ Johor, Malaysia. E-mail: cslong_1@yahoo.com
}

Received: April 11, 2014 Accepted: May 12, 2014 Online Published: June 25, 2014

doi:10.5539/ies.v7n7p85 URL: http://dx.doi.org/10.5539/ies.v7n7p85

\begin{abstract}
This paper examines the relationship between human resource development (HRD) practices and employees' job satisfaction. This study is conducted at a public university in Malaysia. A total of 95 questionnaires were collected out of 1110 distributed, indicating an $8.5 \%$ rate of return. All respondents were academic staff of the university. Four HRD practices which are examined, including i) Training and development, ii) Organization development, iii) Career development and iv) Performance management. The results show that all HRD practices are significantly related to job satisfaction.
\end{abstract}

Keywords: training, career development, performance management, job satisfaction, human resource development

\section{Introduction}

Job satisfaction means the feelings of different employees about the different dimensions of their jobs. Job satisfaction may be the general behavior emerged due to different events at the workplace; it may be a supervisor's behavior, relationship with peers or the work environment (Robbins, 2012). Various factors such as an employee needs and desires, social relationships, job design, compensation, developmental opportunities and aspects of work-life balance is considered to be some of the key factors of job satisfaction (Spector, 1997). The level of satisfaction and dissatisfaction is another aspect which relates to employee job satisfaction. Robbins (2012) stressed that a satisfied workforce can increase organizational productivity through less distraction caused by absenteeism or turnover, few incidences of destructive behavior and lower medical costs.

On the other hand, Rowold (2008) argued that job satisfaction is not only an important indicator of employees' well-being, but is also central for understanding the process of employee turnover. For example, it has been found that job satisfaction explains variance in withdrawal cognitions, turnover intentions, and actual turnovers, independent from organizational commitment. In human resource development literature, job satisfaction is as an important construct representing the employees' interests (Guest, 1999).

In addition, meta-analysis has been conducted to examine how the relationships between the availability of high commitment HR practices, as perceived by employees, and affective commitment and job satisfaction change with age (Kooij et al., 2010). The study also reveals that, in line with social exchange and signaling theories, employees' perceptions of HR practices are positively related to their work-related attitudes and that calendar age influences this relationship largely as expected.

\section{Human Resource Development Practices}

Werner and DeSimone (2011) stress that HRD can be defined as a set of systematic and planned activities designed by an organization to provide its members with the opportunities to learn necessary skills to meet current and future job demands. In a broader sense, HRD seeks to develop people's "knowledge, expertise, productivity, and satisfaction, whether for personal or group/team gain, or for the benefit of an organization, community, nation or ultimately, the whole humanity." HRD activities should begin when an employee joins an organization and continue throughout his or her career, regardless of whether that employee is an executive or a 
worker on an assembly line. HRD programs must respond to job changes and integrate the long-term plans and strategies of the organization to ensure the efficient and effective use of resources. In short, while training and development (T\&D) activities constitute a major part of HRD, activities such as coaching, career development, team building, and OD also are aspects of HRD.

Hassan (2007) argues that there is a belief in HRD that organizations are man-made creatures that supported by human expertise to institute and accomplish the organization goals. The HRD professionals are depending on individual and group, work processes and integrity of the organization. On the other hand, Raiden and Dainty (2006) argue HRD is a summary of all the activities to improve personnel and organization in order to improve the organization efficiency.

Xie and Huang (2010) research about the comparative analysis of HRD among different countries has a different emphasis on dimensions of HRD. This is caused by the different features of the organization, likes the extent of organization's complexity, the significance of human resources efficiency, and the association of HRD. Although the HRD facets may be different compare to each country, the dimensions are mainly related to three main subjects, which are individual development (e.g. Informal or formal training and development activities), career development, performance management and organizational development.

\section{HRD Elements that Affect Job Satisfaction}

There are four HRD elements that affect employee job satisfaction which will be discussed in this section. They are i) Training and Development (T\&D), ii) Organization Development (OD), iii) Career Development, and iv) Performance Management.

\subsection{Training and Development $(T \& D)$}

Training and development (often abbreviated as T\&D) focus on changing or improving the knowledge, skills, and attitudes of individuals. Training typically involves providing employees the knowledge and skills needed to do a particular task or job, though attitude change may also be attempted (e.g., in sexual harassment training). Developmental activities, in contrast, have a longer-term focus on preparing for future work responsibilities while also increasing the capacities of employees to perform their current jobs (Werner \& DeSimone, 2011).

There are currently many organizations offering talented employees training to keep employee current on their job functions and allowing them to learn new skills can be utilized to improve employee satisfaction within the organization (Rice et al., 1991). Besides that, there is also evidence suggests that training is more likely to have a positive effect on employee satisfaction where employers develop formal, structured approaches to training that link skill formation to job tenure, career progression, recognition and reward (Heyes \& Stuart, 1994).

Training is often utilized within organizations for enhancing employees' knowledge, skills, and abilities (KSA) (Arthur et al., 2003). Jen (2009) argued that all organizations rely on highly satisfied and involved employees to achieve organizational goals. This can be done through a well systematic total training plan. Saks (1995) has also found that participating in training enhanced employees' job satisfaction and this finding supported by a study conducted by Georgellis and Lange (2007) in Germany. However, a contradiction of results was found in a study conducted in the Australian franchise sector by Choo and Bowley (2007). Therefore, additional research is necessary to explore the impact and interaction between training and job satisfaction.

Costen and Salazar (2011) stressed that training is one of HR's most visible responsibilities. The opportunity to develop new skills measures the employee's assessment of the organization's training program. Training involves providing employees with the basic knowledge and skills they need to perform their duties to the company's standards.

There have been many studies investigating the relationship between job satisfaction and training and development. There was a study of Yap and Holmes (2010) which investigated the association between employees' perceptions of diversity training (DT) existence and effectiveness with organizational commitment (OC), and career satisfaction (CS). The paper also examined the linkages between diversity training, organizational commitment, and career satisfaction based on survey responses from managers, professionals, and executives. The survey included questions about employees' perceptions of their work experiences and outcomes and their organizations' diversity practices. Comparisons of means as well as multivariate regression analyses were undertaken. In their study, they found that employees who perceived diversity training to be effective were significantly more committed to their organizations and more satisfied with their careers than employees who perceived DT to be ineffective or non-existent. The paper found that employees' OC and CS are higher when they perceived DT to be effective. Factors associated with OC and CS are explored based on employees' perceptions of the availability and effectiveness of DT. 


\subsection{Organization Development (OD)}

Organization Development (OD) is defined as the process of enhancing the effectiveness of an organization and the well-being of its members through planned interventions that apply behavioral science concepts. OD is a response to identify the need for change, using specific strategies to alter elements such as the beliefs, attitudes, values, and structure of organizations. The change will help organizations adapt to the new markets and the challenges ahead (Werner \& DeSimone, 2011).

Similarly, the relation between perceived organizational change efficacy and job satisfaction should be positive and meaningful. The reason for this assumption is that the perceived efficacy of change is positioned at the level of work situation determinants of job satisfaction, as it is related to the perceived impact of the changes in the workplace. The work situation determinants are the main predictors of job satisfaction (George \& Jones, 2008).

Mihaela et al. (2001) study analyzed the educational institution in terms of curriculum and human resources, school life, material and financial resources. In the study, it involved all unit employees, support staff, teacher and also parents of enrolled children. After processing the information obtained from surveys concerning job satisfaction and organizational communication and parent questionnaires on kindergarten-family partnership, an organizational development program has been developed. Organizational development program involves intervention in three main areas: developing educational partnerships, promoting the image of the kindergarten in the community and training of human resources. The need for OD mainly focuses on improving organizations for their own benefit and for the benefit of their employees. Therefore, employees that appreciate and involve in the change process will gain satisfaction in their work.

\subsection{Career Development}

Many organizations implement Career Development Programs in the workplace to enable them to retain good employees (Merchant Jr., 2010). This type of program educates employees on how to achieve their own career goals and at the same time contribute to the organization. Organizations with such programs claim they retain a greater number of employees. Employees' career growth is a key strategic asset for many far-sighted organizations (Fink, 1992). Career development is not purely about getting promoted or moving up the corporate ladder, but rather about getting to be the best an individual can be and finding a place in an organization where they can express excellence and contribute to the goals of the organization. Career development also encompasses "horizontal" movement (lateral job transfers) within the organization. Today's employees are demanding more from their work in terms of fulfillment and personal satisfaction. Employees now would prefer to be empowered and gain an opportunity for self development.

\subsection{Performance Management}

Another element that affects employee job satisfaction is performance management. It is important to study the job satisfaction and job performance relationship for several reasons (e.g. see Brief, 1998; Cropanzano \& Wright, 2001). For example, satisfaction is important for worker health and well-being, and organizations have control over job design features that influence both satisfaction (e.g. pay, procedural justice) and performance (e.g. resources, training). As such, organizations have the latitude to affect both satisfaction and performance, and due to the potential strength of the relationship (Petty et al., 2005), interventions could result in both a healthier workforce and increased effectiveness.

Bryan et al. (2008) examined the relationship between job satisfaction and task and contextual performance. Specifically, it assessed this relationship for the overall as well as facets of job satisfaction. Four hundred and forty-four employees in a manufacturing plant involved in the study on measures of their job satisfaction. Results indicate that the there was a stronger relationship between satisfaction with supervision and contextual performance compared to task performance. This result indicated the importance of performance management and overall job satisfaction. The relationship is significant and worth to be explored further.

Colin and John (2008) investigate the influence of performance-related pay on several dimensions of job satisfaction. The outcome of the study shows that performance-related pay allows increased opportunities for worker optimization and does not generally demotivate workers or crowd out intrinsic motivation.

Performance pay has been shown to increase productivity in some settings (Lazear, 2000), and may itself increase job satisfaction. This happens when employees witness gains in confidence, pride and self-worth. However, performance pay can also decrease job satisfaction (Fernie \& Metcalf, 1999; Lazear, 2000; Long et al., 2013). As a result, this may in turn lead to discontentment among the less productive workers and an overall reduction in worker morale. Employees are generally more satisfied with their jobs if they perceive their pay is fairly distributed (Brown, 2001). Frey and Jegen (2001) explain that performance pay may be viewed by 
employees as an element of control rather than support. Thus, as performance management often relates to employee reward and compensation, it remains an empirical question whether performance pay increases or decreases job satisfaction on average.

\subsection{Hypothesis}

Based on the above literature review, four hypotheses are developed as below:

H1: Training and Development practice has significant impact on academic staff's job satisfaction.

H2: Organization Development has significant impact on academic staff's job satisfaction.

H3: Career Development has significant impact on academic staff's job satisfaction.

H4: Performance Management has significant impact on academic staff's job satisfaction.

\section{Research Method}

\subsection{Research Design}

In this study, quantitative and statistical methods such as regression, quantitative analysis and statistical test will carry out to investigate the relationships from the data. Quantitative research is based on the measurement of quantity or amount and it is applicable to the facts that can be conveyed in terms of quantity.

The sample of study in this research was taken at a public university in Malaysia. The name of the university is withheld as requested by the management of the University. Therefore, in this report the university is named $\mathrm{ABC}$. First, $\mathrm{ABC}$ has been upgraded as a Research University recently, and its organizational system has been altered. Secondly, ABC is also the lead of technology education in Malaysia, therefore the development of the $\mathrm{ABC}$ is very important. Academic staffs are the main resource of university, which their contribution to the university is not only educate students but also the development of the university. Thus, it is important to study the job satisfaction of academic staffs which it is believed that high job satisfaction will bring high job commitment and loyalty. Besides, the vision of $\mathrm{ABC}$ is to be recognized as a world-class center of academia and technological excellence, and the mission of $\mathrm{ABC}$ is to be a leader in the development of human capital and innovative technologies that will contribute to the nation's wealth creation. In order to achieve the mission and vision of $\mathrm{ABC}$, it is also needed to explore the main resource of $\mathrm{ABC}$, which is academic staff. This study studies the impact of Human Resource Development (HRD) on ABC academic staff's job satisfaction.

\subsection{Instrumentation}

To test the conceptual model and research questions, a survey was conducted among academic staffs at ABC. The instrument used is the questionnaire and it is sent via email with clear instructions given to the samples. The reason it was sent via email is because it could reach a wide geographic area quickly, which could ensure representativeness and generalization of the findings. Moreover, by sending it via email, the respondents were able to answer the survey at their own place. The completion of these questionnaires was entirely voluntary and responses were anonymous and were treated with strictest confidentiality.

The survey covered the topics of training and development; organization development, career development, performance management, and overall satisfaction. The questions ranged from strongly disagree to strongly agree on a 5-point Likert scale. In addition, the following seven demographic items were included: sex, age, faculty, qualification, designation, year of service, and employment status. The instrument is adapted from an instrument used by Johnson (2011), Torraco and Hoover (2005) and Barnett and Bradley (2007).

\section{Data Analysis}

\subsection{Sample Size}

A total of 95 questionnaires were collected from 1110 distributed, indicating an $8.5 \%$ rate of return. Green (1991) provides a comprehensive overview of the procedures used to determine regression sample sizes. He suggests $\mathrm{N}>$ $50+8 \mathrm{~m}$ (where $\mathrm{m}$ is the number of independent variables) for testing the multiple correlations. There are four independent variables in this study, therefore, the sampling size; $\mathrm{N}$ should more than $50+8(4), \mathrm{N}>82$. In this study there are 95 set data which is more than 82 (the sampling size by Green, 1991), therefore it is adequate to conduct statistical analysis.

\subsection{Results}

\subsubsection{Correlation Analysis}

Table 1 shows the correlation between independent variable and dependent variable in this study. 
Table 1. Spearman-rho correlation between variable

\begin{tabular}{|c|c|c|c|c|c|}
\hline \multicolumn{6}{|c|}{ Spearman's rho Correlations } \\
\hline & $\begin{array}{c}\text { Training \& } \\
\text { Development }\end{array}$ & $\begin{array}{l}\text { Organization } \\
\text { Development }\end{array}$ & $\begin{array}{c}\text { Career } \\
\text { Development }\end{array}$ & $\begin{array}{l}\text { Performance } \\
\text { Management }\end{array}$ & $\begin{array}{l}\text { Overall Job } \\
\text { Satisfaction }\end{array}$ \\
\hline $\begin{array}{c}\text { Training \& } \\
\text { Development }\end{array}$ & 1 & & & & \\
\hline $\begin{array}{l}\text { Organization } \\
\text { Development }\end{array}$ & $0.87^{* *}$ & 1 & & & \\
\hline $\begin{array}{c}\text { Career } \\
\text { Development }\end{array}$ & $0.49^{* *}$ & $0.62^{* *}$ & 1 & & \\
\hline $\begin{array}{l}\text { Performance } \\
\text { Management }\end{array}$ & $0.48^{* *}$ & $.60^{* *}$ & $.72^{* *}$ & 1 & \\
\hline $\begin{array}{l}\text { Overall Job } \\
\text { Satisfaction }\end{array}$ & $0.50^{* *}$ & $.65^{* *}$ & $.76^{* *}$ & $.64^{* *}$ & 1 \\
\hline
\end{tabular}

This table consists of five variables in which overall job satisfaction is the dependent variable, and the following variables i) training and development, ii) organization development, iii) career development, and iv) performance management are the independent variables. Overall, most of the HRD practices have strong correlation with academe's overall job satisfaction, which the highest was 0.76 and the lowest was 0.50 . The highest correlation between independent and dependent variable was between overall job satisfaction and career development, with the spearman-rho coefficient 0.76 . On the other hand, the lowest correlation between independent variable and the dependent variable was overall job satisfaction with training and development, which was 0.5 spearman-rho coefficient.

\subsubsection{Simple Linear Regression Analysis}

Table 2 shows the simple linear regression between independent and dependent variables, which the independent variables consist of training and development, organization development, career development and performance management; dependent variable is overall job satisfaction. It is found that these four independent variables: i) Training \& Development $(\beta=0.42, p=0.00)$, ii) Organization Development $(\beta=0.65, p=0.00)$, iii) Career Development $(\beta=0.77, \mathrm{p}=0.00)$; and iv) Performance Management $(\beta=0.65, \mathrm{p}=0.00)$ have significant positive effects on overall job satisfaction.

Table 2. Simple linear regression between independent and dependent variable

\begin{tabular}{ccccc}
\hline Variable & Standardized Coefficients & \multirow{2}{*}{$\mathrm{t}$} & Sig. \\
\cline { 1 - 2 } & Beta & & \\
\hline Training \& Development & 0.42 & 4.47 & 0.00 \\
Organization Development & 0.65 & 8.18 & 0.00 \\
Career Development & 0.77 & 11.60 & 0.00 \\
Performance Management & 0.65 & 8.31 & 0.00 \\
\hline
\end{tabular}

\subsubsection{Multiple Regression Analysis}

Table 3 shows the summary result of the multiple regression analysis. There is no multi-collinearity problem when the tolerance level is more than 0.1 and VIF is less than 10 (Ho, 2006). It can be seen that all the independent variables' tolerance level is more than 0.1 and the VIF is less than 10 , therefore, there is no significant relationship among the independent variable. 
Table 3. Tolerance and VIF test for multi-collinearity

\begin{tabular}{|c|c|c|}
\hline \multicolumn{3}{|l|}{ Coefficients $^{\mathrm{a}}$} \\
\hline \multirow{2}{*}{ Variable } & \multicolumn{2}{|c|}{ Collinearity Statistic } \\
\hline & Tolerance & VIF \\
\hline Training \& Development & 0.79 & 1.27 \\
\hline Organization Development & 0.54 & 1.87 \\
\hline Career Development & 0.41 & 2.46 \\
\hline Performance Management & 0.47 & 2.15 \\
\hline
\end{tabular}

a. Dependent Variable: OJS.

Table 4 shows the F statistic for the final model is 41.01 with a P-value of 0.00 , which indicating a significant model. The significant model indicates that there are effects between four independent variable i) Training \& development, ii) Organization development, iii) Career development and iv) Performance management) with $\mathrm{R}=$ 0.80 . These four independent variables explain $64.6 \%$ of the variance in overall job satisfaction $\left(R^{2}=0.646\right)$ and $63 \%$ of the variance of overall job satisfaction in real populations (Adjusted $\mathrm{R}^{2}=0.63$ ).

Table 4. Multiple regression of independent variables on dependent variable (overall job satisfaction)

\begin{tabular}{cccccc}
\hline $\mathrm{R}$ & $\mathrm{R}^{2}$ & Adjusted $^{2}$ & Std. Error of the Estimate & $\mathrm{F}$ & Sig. F \\
\hline $0.80^{\mathrm{a}}$ & 0.646 & 0.63 & 0.37 & 41.01 & $0.00^{\mathrm{b}}$
\end{tabular}

a. Predictors: (Constant), Performance Management, Training \& Development, Organization Development, Career Development.

b. Dependent Variable: Overall Job Satisfaction.

Table 5 shows the multiple regressions between independent variables and a dependent variable. It is found that among four independent variables, career development predict the most on academic staff's overall job satisfaction, with $\beta=0.49$. Organization development $(\beta=0.21)$ shows the second highest predictor on academic staff's overall job satisfaction, and Training and development show the least prediction on academic staff's job satisfaction, which $\beta=0.07$ only.

Table 5. Multiple regressions between independent variables and dependent variable

\begin{tabular}{ccc}
\hline Variable & Standardized Coefficients & \multirow{2}{*}{$\mathrm{T}$} \\
\cline { 1 - 2 } (Constant) & Beta & \\
\cline { 1 - 2 } Training \& Development & 0.07 & 1.43 \\
Organization Development & 0.21 & 2.47 \\
Career Development & 0.49 & 5.00 \\
Performance Management & 0.15 & 1.65 \\
\hline
\end{tabular}

a. Dependent variable: Overall Job Satisfaction.

\section{Discussion and Conclusion}

The main purpose of this study is to investigate the impact of HRD practices on academic staff's job satisfaction. The four independent variables are training and development, organization development, career development and performance management. The research was conducted on $\mathrm{ABC}$ academic staff. The discussion of research 
questions will be presented in this chapter, followed by research conclusion and implications. The limitations of this research and recommended for future studies are included towards the end of this report.

Hypothesis 1: Training and Development practice has significant impact on academic staff's job satisfaction.

Training is a systematic and planned coaching activity to encourage learning, while developmental practices are preparing for the organization's future. The result in this study support the hypothesis 1 that training and development practice $(\beta=0.42, p=0.00)$ has significantly impacted on academic staff's job satisfaction, and the result also consistent with previous study, such as the staff survey of the University of Virginia (2011) also revealed that training and development practices were statistically significant in determining overall job satisfaction. Furthermore, a previous study from Costen and Salazar (2011) also stated that training and development is a critical element that affects job satisfaction. A research from Taormina (1999) also revealed that training was a crucial predictor of job satisfaction. Another previous study from Yap et al. (2010) also found that the employee that recognized diversity training to be effective has higher job satisfaction. Therefore, proper training should be given to academic staffs from time-to-time, to upgrade and update their skills so as to enhance their capabilities and abilities.

Hypothesis 2: Organization Development has significant impact on academic staff's job satisfaction.

Organization development provides organizational change to enhance improvement in the organization through enabling organization members to manage their team an organizational culture effectively. The result in this study supports hypothesis 2 that organization development $(\beta=0.65, p=0.00)$ has significant impact on academic staff's job satisfaction and is consistent with previous study, such as a study from Johnson (2011) revealed that organization development will not only increase employees' job satisfaction but also foster a more efficient working environment. Besides that, Korsvold (2010) also revealed that the OD process was promoting employees' job satisfaction.

Hypothesis 3: Career Development has significant impact on academic staff's job satisfaction.

Hite and McDonald (2008) found that career development is an ongoing process of planning and directed action toward personal work and life goals. The result supports hypothesis 3 that career development $(\beta=0.77, p=$ 0.00 ) significantly affects academic staff's job satisfaction and is consistent with previous study, such as Ko (2012) revealed that there is significant correlation between job satisfaction and career development. In addition, a previous research from Barnett and Bradley (2007) also showed that career development is correlated significantly with employees' career satisfaction. Furthermore, the University of Virginia Report (2011) also showed that career development is significantly correlated with academic staff's job satisfaction.

Hypothesis 4: Performance Management has significant impact on academic staff's job satisfaction.

Performance management denotes the continuing route that consists of goal setting, coaching and developing employees, providing feedback, assessing employee's performance formally, and linking performance to recognition and rewards (Smither, 2009). The result of this study shows that performance management $(\beta=0.65$, $p=0.00$ ) has significant impact on academic staff's job satisfaction. Similarly, Edwards et al. (2008) found that there was statistically significant positive relationship between performance and overall job satisfaction.

Based on the results shown in Table 5, career development predicts the most on academic staff's overall job satisfaction, with $\beta=0.49$. Organization development $(\beta=0.21)$ shows the second highest predicted on academic staff's overall job satisfaction, and then follow by performance management $(\beta=0.15)$. Training and development $(\beta=0.07)$ show the lowest level of prediction overall job satisfaction. Performance management shows the second lowest beta value, $\beta=0.15$. In other words, among the four HRD practices in this study, performance management only contributes a little prediction on academic staff job satisfaction. A previous study by Judge et al. (2001) showed that the relationship between performance management and job satisfaction may vary based on job complexity. The findings show that when the target subject is scientist, there will be lower relations. Since ABC is an engineering-based university and has been upgraded as a Research University recently, therefore the job task of academic staff can consider as high complexity task, and this may be the reason cause performance management show the low level of impact on academic staff's job satisfaction among four independent variables.

There was a project regarding revisit and fine tune the KPI of ABC academic staffs by Selamat (2011) to explore the limitations of the current performance appraisal system, KPI and the factors academic staffs considered that will affect research productivity in $\mathrm{ABC}$, and also investigate the accuracy appraisal of the current evaluation system (e-LPPT) with satisfactory feedback. From the findings of the project, it is found that there is low performance in publication. The second problem is that there is no involvement of individual staff in KPI 
formulation. The third problem is that the strategic planning has shown that both the faculty and research alliance have their different KPIs, which require the academic staff to participate in both units to help in meeting their KPIs.

In the project of Selamat (2001), the author comment that since the KPI on scholarly publication are considered new by many of the respondents, it will be better for the policy makers not to target high numbers of paper from an academic staff. The author also suggests that the policy makers or the management should involve individual academic staff in designing their KPIs. In addition, he also thinks that the e-LPPT should be linked with the Research Management Centre (RMC) database and should include a section for scholarly publication and citation, and also should be able to retrieve an academic staff data from all subscribed journals. A feedback mechanism should be included in the e-LPPT system to facilitate improvement. The university should provide more training on publications and also team work should be encouraged by having a research culture.

Training and development show the least predict on academic staff's job satisfaction, which $\beta=0.07$ only. A previous study from Choo and Bowley (2007) revealed that the efficacy and effectiveness of a training program are relying on assessment of training quality, course design and learning experience, and also mentioned that job satisfaction is not affected by training and development. Furthermore, $\mathrm{Ng}$ et al. (2010) argue that the critical element of teaching was personal experience and not training and development practices. Besides, there is also some academia comment that the amount of training programs that provided by the university is sufficient, but it is contributing marginal effect on their work output. As we know Academe work orientation does not like business organization, each academic staff has different projects and from different majors, therefore, the training programs may not fulfill each staff's needs.

\subsection{Implication for Practice}

The study has found that academic staff who are high level of satisfaction with the career development practices are more potentially to be high job satisfaction. From the managerial perspective, the university can focus on career development program and organizational development practices in order to enhance academic staff's job satisfaction. For example, the career and development unit of $\mathrm{ABC}$ can review the current career development programs that provided to academic staff, to find out any improvement can be made, so that the program will enlighten more academic staff, and eventually improve their job satisfaction.

In addition, it is also found that organization development practice is also another crucial element predicting academic staff's job satisfaction. From the managerial perspective, the university can assess the effectiveness of decision making process of university administration, and improve it. Besides that, when there are changes brought to the university, the administration should make the changing process more stable, so that the academic staff can accept and adapt the new changes more easily, and it will reduce the friction and stress among the university administration and faculty members, and ultimately increase academic staff's job satisfaction.

On the other hand, training and development and performance management show the lowest effect on predicting academic staff's job satisfaction among the four HRD practices that investigated in this study. From the managerial perspective, the university can investigate the training and development program that provided by university or faculties in order to explore the effectiveness of training and development programs, so that the provided training and development program is to fulfill the needs of academic staff. On the other hand, the university also can re-evaluate the current academic staff's performance evaluation system, in order to improve the system to evaluate effectively and preciously.

\subsection{Implication for Research}

Kooij (2010) suggested that HRD are important determinants of job satisfactions. In this study, the empirical evidence reaffirmed the suggestion of hypotheses in which there is a relationship between HRD and job satisfaction. Therefore, the HRD elements should not be ignored in academic research in investigating the job satisfaction for employees, not limiting to academic staff. In addition, the HRD can be the stepping stone for researchers to gain more insights on the HRD effects on job satisfaction.

The future research could make several extensions of current study. First, the future research could use focus group interviews to conduct this research, to make a qualitative study with deeper understanding. Moreover, the future study can extend to all Malaysia universities such as, in particular private universities, public universities and research universities.

Second, it is also interesting to perform a comparative study between private universities and public universities to further understand the implication of HRD practices on academician job satisfaction. This is important because researcher believes the organizational system and performance management systems in private 
universities may be different.

\subsection{Limitations}

As with any study, there are limitations to this research. The research is carried out at $\mathrm{ABC}$ in context of $\mathrm{ABC}$ culture, so the generalization of results is limited to $\mathrm{ABC}$. Therefore, it can only be considered as a census from a regional perspective and might not reflect job satisfaction of to the entire local universities in the country.

Furthermore, the factors behind job satisfaction may be different, or at least have different importance, in different cultures. Academicians are the respondents in this study; therefore, the result of this study may not be applicable to other fields or careers. Besides, the perspective studied in research only focuses on HRD practices. There are also other elements that affect job satisfaction.

\section{Acknowledgements}

The authors wish to acknowledge the Malaysian Ministry of Higher Education and Universiti Teknologi Malaysia under the Research Grant (Vot.4F349) for supporting and sponsoring this publication.

\section{References}

Arthur, W., Bennet, W., Edens, P. S., \& Bell, S. T. (2003). Effectiveness of training in organizations: A meta-analysis of design and evaluation features. Journal of Applied Psychology, 88, 234-245. http://dx.doi.org/10.1037/0021-9010.88.2.234

Barnett, B. R., \& Bradley, L. (2007). The impact of organisational support for career development on career $\begin{array}{lllll}\text { satisfaction. } & \text { Career Development }\end{array}$ http://dx.doi.org/10.1108/13620430710834396

Baron, R. A. (1976). Behavior in Organisations. Allyn \& Bacon, Boston, MA.

Brief, A. P. (1998). Attitudes in and Around Organizations. Thousand Oaks, CA: Sage.

Brown, M. (2001). Unequal pay, unequal responses? Pay referents and their implications for pay level satisfaction. Journal of Management Studies, 38, 879-896. http://dx.doi.org/10.1111/1467-6486.00263

Bryan, D. E, Suzanne, T., Winfred, A, J., \& Arlette, D. D. (2008). Relationships between Facets of Job Satisfaction and Task and Contextual Performance. Applied Psychology: An International Review, 57(3), 441-465. http://dx.doi.org/10.1111/j.1464-0597.2008.00328.x

Choo, S., \& Bowley, C. (2007). Using training and development to affect job satisfaction within franchising. Journal of Small Business and Enterprise Development, 14, 339-52. http://dx.doi.org/10.1108/14626000710746745

Colin, G., \& John, S. H. (2008). Does performance pay increase job satisfaction? Economica, 75, 710-728.

Costen, W. M., \& Salazar, J. (2011). The Impact of Training and Development on Employee Job Satisfaction, Loyalty, and Intent to Stay in the Lodging Industry. Journal of Human Resources in Hospitality \& Tourism, 10(3), 273-284. http://dx.doi.org/10.1080/15332845.2011.555734

Cropanzano, R., \& Wright, T. A. (2001). When a "happy" worker is really a "productive" worker: A review and further refinement of the happy-productive worker thesis. Consulting Psychology Journal: Practice and Research, 53, 182-199. http://dx.doi.org/10.1037/1061-4087.53.3.182

Fernie, S., \& Metcalf, D. (1999). (Not) hanging on the telephone: Payment systems in the new sweatshop. Advances in Industrial Relations, 9, 23-68.

Fink, S. (1992). High commitment workplaces. New York: Quorum.

Frey, B. S., \& Jegen, R. (2001). Motivational crowding theory. Journal of Economic Surveys, 15, 589-611. http://dx.doi.org/10.1111/1467-6419.00150

George, J., \& Jones, G. (2008). Understanding and managing organizational behavior (5th ed.). Upper Saddle River, New Jersey: Pearson Prentice Hall.

Georgellis, Y., \& Lange, T. (2007). Participation in continuous, on-the-job training and the impact on job satisfaction: Longitudinal evidence from the German labour market. International Journal of Human Resource Management, 18, 969-985. http://dx.doi.org/10.1080/09585190701321112

Green, S. B. (1991). How many subjects does it take to do a regression analysis. Multivariate behavioral research, 26, 499-510. http://dx.doi.org/10.1207/s15327906mbr2603_7

Guest, D. E. (1999). Human resource management-the worker's verdict. Human Resource Management Journal, 
9, 5-25. http://dx.doi.org/10.1111/j.1748-8583.1999.tb00200.x

Hassan, A. (2007). Human resource development and organizational values. Journal of European Industrial Training, 31, 435-448. http://dx.doi.org/10.1108/03090590710772631

Heyes, J., \& Stuart, M. (1994). Placing symbols before reality? Re-evaluating the low skills equilibrium. Personnel Review, 23(5), 34-47. http://dx.doi.org/10.1108/00483489410067763

Hite, L. M., \& Mcdonald, K. S. (2008). A new era for career development and HRD. Advances in Developing Human Resources, 10, 3-7. http://dx.doi.org/10.1177/1523422307310103

Johnson, A. (2011). Organization Change in Higher Education: Transforming Institutions of Learning into Learning Organizations (Unpublished dissertation). The College of St. Scholastica.

Judge, T. A., Hanisch, K. A., \& Drankoski, R. D. (1995). Human resources management and employee attitudes. In G. R. Ferris, S. D. Rosen, \& D. T. Barnum (Eds.), Handbook of human resources management (pp. 574-596). Oxford: Blackwell Publishers.

Ko, W. H. (2012). The relationships among professional competence, job satisfaction and career development confidence for chefs in Taiwan. International Journal of Hospitality Management, 31, 1004-1011. http://dx.doi.org/10.1016/j.ijhm.2011.12.004

Kooij, D. T. A. M., Jansen, P. G. W, Dikkers, J. S. E., \& Lange, A. H. D. (2010). The influence of age on the associations between HR practices and both affective commitment and job satisfaction: A meta-analysis, Journal of Organizational Behavior, 21, 1111-1136. http://dx.doi.org/10.1002/job.666

Korsvold, T., Hansson, L., \& Lauvsnes, A. (2010). Job satisfaction and extensive participation processes in organizational development-A case study from the Norwegian petroleum industry. In G. S. Bris (Ed.), Reliable Risk and Safety (pp. 2215-2221). Taylor \& Francis Group: London.

Lazear, E. P. (2000). Performance pay and productivity. American Economic Review, 90(13), 46-61.

Locke, E. A. (1976). The nature and causes of job satisfaction. In M. D. Dunnette (Ed.), Handbook of industrial and organizational psychology (pp. 1297-1349). Chicago, IL: Rand McNally.

Long, C. S., Kowang, T. O., Ismail, W. K. W., \& Rasid, S. Z. A. (2013). A review on performance appraisal system: An ineffective and destructive practice? Middle East Journal of Scientific Research, 14(7), 887-891.

Merchant Jr., R. C. (2010). The role of career development in improving organizational effectiveness and employee development. Florida Department of Law Enforcement.

Mihaela, S., Adela, M., Adriana-Elena, T., \& Monica, F. (2001). An organizational development program in the preschool educational institution. Procedia-Social and Behavioral Sciences, 15, 998-1002. http://dx.doi.org/10.1016/j.sbspro.2011.03.228

Petty, G. C., Brewer, E. W., \& Beth, B. (2005). Job satisfaction among employees of a youth development organization. Child and Youth Care Forum, 34, 57-73. http://dx.doi.org/10.1007/s10566-004-0882-8

Raidén, A. B., \& Dainty, A. R. J. (2006). Human resource development in construction organisations: An example of a "chaordic" learning organisation? Learning Organization, 13, 63-79. http://dx.doi.org/10.1108/09696470610639130

Rice, R. W., Gentile, D. A., \& McFarlin, D. B. (1991). The Clash of Cultures: Managers Managing Professionals. Harvard Business School, Boston, MA.

Robbins, S. P. (2012). Organizational Behaviour (15th ed.). Upper Saddle River, New Jersey: Pearson Education, Inc.

Rowold, J. (2008). Multiple effects of human resource development interventions. Journal of European Industrial Training, 32(1), 32-44. http://dx.doi.org/10.1108/03090590810846557

Saks, A. M. (1995). Longitudinal field investigation of the moderating and mediating effects of self-efficacy on the relationship between training and newcomer adjustment. Journal of Applied Psychology, 80, 211-225. http://dx.doi.org/10.1037/0021-9010.80.2.211

Spector, P. (1997). Job Satisfaction: Application, Assessment, Cause and Consequences. London: Sage Publications. http://dx.doi.org/10.4135/9781452231549

Taormina, R. J. (1999). Predicting employee commitment and satisfaction: The relative effects of socialization and demographics. International Journal of Human Resource Management, 10(6), 1060-1076. 
http://dx.doi.org/10.1080/095851999340125

Werner, J. M., \& DeSimone, R. L. (2011). Human Resource Development (5th ed.). Cengage Learning.

Yap, M., \& Holmes, M. R. (2010). The relationship between diversity training, organizational commitment, and career satisfaction. Journal of European Industrial Training, 34(6), 519-538. http://dx.doi.org/10.1108/03090591011061202

\section{Copyrights}

Copyright for this article is retained by the author(s), with first publication rights granted to the journal.

This is an open-access article distributed under the terms and conditions of the Creative Commons Attribution license (http://creativecommons.org/licenses/by/3.0/). 